\title{
Rheological and Molecular Characterization of Rubberized Asphalt Emulsion
}

\author{
Md. Nafiur Rahman, Md. Tanvir Sarkar, and Mostafa Elseifi* \\ Department of Civil and Environmental Engineering, Louisiana State University, Baton Rouge, LA 70803
}

\begin{abstract}
An experimental study was conducted to evaluate the rheological and molecular characterization of rubberized asphalt emulsion. One rubberized asphalt emulsion and an asphalt rubber (CRS-2TR and AC20-TR) and two conventional emulsions (CRS-2 and CRS-2P) were evaluated. The emulsions were characterized by conducting rheological and physical testing. The influence of adding crumb rubber on the binder chemical composition was investigated in the laboratory using Fourier Transform Infrared Analysis (FTIR) on the original, Rolling-Thin Film Oven (RTFO) and Pressure Aging Vessel (PAV)-aged binder residues. Results showed that CRS-2TR and AC20-TR had lower carbonyl and sulfoxide indices indicating better resistance to aging compared to conventional asphalt emulsions. Results of High-Pressure Gel Permeation Chromatography (HP-GPC) on the original, RTFO and PAV-aged binder residues showed that CRS-2TR and AC20-TR had similar High-Molecular Weight (HMW) content compared to that of conventional asphalt emulsions indicating similar susceptibility to brittleness with age.
\end{abstract}

\section{Introduction}

Pavement maintenance is a type of preventive measure that allows to extend pavement functional conditions throughout its lifespan. In order to avoid progressive deterioration and costly rehabilitation of the pavement structure, many agencies including the Louisiana Department of Transportation and Development (LaDOTD) have implemented pavement preservation programs, which not only arrest minor deteriorations but also reduce the risk of extensive deteriorations in the future [1]. Pavements with age related distresses are commonly treated with preservation techniques such as the application of thin overlays and resurfacing [2]. Chip seals, also referred to as seal coats or Asphalt Surface Treatment (AST), have been used for more than 50-year in the United States given its low initial cost compared to asphalt concrete (AC) overlay [3]. Chip seals are typically favored on relatively low traffic roadways with the aim to reduce the permeability of the pavement surface, improve skid resistance, eliminate raveling, and retard oxidation [4].

Asphalt rubber chip sealing had been used by many state agencies such as Arizona, California, and Florida [5]. It has been reported that using crumb rubber to modify asphalt cement improve its performance due to the interaction of Crumb Rubber Modifier (CRM) with the base asphalt binder. Researchers have studied the physical and rheological properties of hot applied crumb rubber modified binder (CRMB) [6, 7]. It was found that crumb rubber interaction improved the physical properties, viscosity, and rheological properties of CRMB, resulting in numerous advantages such as improved durability, cracking resistance, and resistance to reflective cracking and rutting [8]. However, the hot application of asphalt rubber at an elevated temperature of $190-218^{\circ} \mathrm{C}\left(375-425^{\circ} \mathrm{F}\right)$ is a safety concern for many states and no literature was found supporting the cold application of CRMB. Therefore, the use of rubberized emulsion may be considered as a promising alternative since it is installed at the same temperature of a standard emulsion, which is typically between 60 and $71^{\circ} \mathrm{C}(140$ to $160^{\circ} \mathrm{F}$ ).

The primary objective of this study was to characterize and compare the rheological and molecular properties of rubberized emulsion, asphalt rubber, and conventional emulsions in terms of performance grade and molecular and fractional compositions. These results will be helpful to understand the potential benefits of using rubberized emulsion in chip seal applications.

\section{Methodology}

\subsection{Materials}

As shown in Table 1, the types of emulsion investigated in this study included a rubberized asphalt emulsion (CRS-2TR), two conventional emulsions (CRS-2 and CRS-2P), and an asphalt rubber (AC20-TR), which is designed to be used in hot chip seal application. For the production of the rubberized asphalt emulsion and asphalt rubber, recycled tires were collected and ground to minus 30 mesh size to produce the crumb rubber. The crumb rubber was screened to remove metal and fibers

\footnotetext{
* Corresponding author: elseifi@1su.edu
} 
and was added to asphalt cement at $5 \%$ by weight using an absorption process.

\subsection{Laboratory testing}

\subsubsection{Superpave binder testing}

The binder residues for the emulsions were prepared as per AASHTO PP 72 Method A and were characterized by rheological testing such as dynamic shear rheometry and bending beam rheometer according to AASHTO T 315 and AASHTO $\mathrm{T}$ 313, respectively. The final Superpave Performance Grade (PG) for the binders was obtained as per AASHTO M 320-09 (Standard Specification for Performance-Graded Asphalt Binder).

Table 1. Description of test materials.

\begin{tabular}{|c|c|}
\hline Sample ID & Description \\
\hline CRS-2 & $\begin{array}{c}\text { Conventional emulsified binder with no } \\
\text { polymer }\end{array}$ \\
\hline CRS-2P & Polymer-modified emulsified binder \\
\hline CRS-2TR & Crumb rubber modified emulsified binder \\
\hline AC20-TR & Crumb rubber modified asphalt binder \\
\hline
\end{tabular}

\subsubsection{Fourier transform infrared spectroscopy}

A Fourier Transform Infrared (FTIR) analysis was performed in order to identify the structural and functional groups present in the original, RTFO, and PAV-aged binder residues. The spectra were obtained by using a diamond single reflection attenuated total reflectance (ATR) instrument. Different indices such as aromatic, aliphatic, carbonyl, and sulfoxide indices for the binder residues were calculated using the equations presented in Table 2 [9].

Table 2. Definitions of FTIR-based indices [9].

\begin{tabular}{|c|c|c|c|}
\hline Group & $\begin{array}{l}\text { Name of } \\
\text { Index }\end{array}$ & Equations & $\begin{array}{c}\text { Equation } \\
\text { Number }\end{array}$ \\
\hline \multirow{2}{*}{$\begin{array}{l}\text { Structural } \\
\text { Group }\end{array}$} & $\begin{array}{l}\text { Aromatic } \\
\text { Index }\left(\mathrm{I}_{\mathrm{Ar}}\right)\end{array}$ & $A_{1600} / \sum A$ & (1) \\
\hline & $\begin{array}{l}\text { Aliphatic } \\
\text { Index }\left(\mathrm{I}_{\mathrm{Al}}\right)\end{array}$ & $\left(A_{1460}+A_{1370}\right) / \sum A$ & (2) \\
\hline \multirow{2}{*}{$\begin{array}{c}\text { Functional } \\
\text { Group }\end{array}$} & $\begin{array}{c}\text { Carbonyl } \\
\text { Index } \\
\left(\mathrm{I}_{\mathrm{C}=\mathrm{O}}\right)\end{array}$ & $A_{1700} /$ & (3) \\
\hline & $\begin{array}{c}\text { Sulfoxide } \\
\text { Index } \\
\left(\mathrm{I}_{\mathrm{S}=\mathrm{O}}\right) \\
\end{array}$ & $A_{1030} / \sum A$ & (4) \\
\hline
\end{tabular}

Where, $\sum A=$ summation of area of spectral bands between 600 and $2,000 \mathrm{~cm}^{-1}$.

\subsubsection{High Pressure Gel Permeation Chromatography (HP-GPC)}

HP-GPC was conducted for the original, RTFO, and PAV-aged binders using an EcoSEC high-performance GPC system equipped with a differential refractive index detector (RI) and an auto injector. A set of three microstyragel columns were used to perform separation of the molecular components.

The molecular weight distribution was divided into two fractions, a high molecular weight fraction (HMW) and a low molecular weight fraction (LMW). The HMW fraction included the components with molecular weights of greater than or equal to 3,000 Daltons. The LMW fraction contained the components with molecular weights less than 3,000 Daltons. The HP-GPC curves were integrated, and the areas were normalized over the total area of the chromatogram. The expected error in the measured molecular fractions is around $0.2 \%$ or less. Two replicates were measured for each binder residue and the average is presented.

\section{Results and analysis}

\subsection{Superpave binder testing}

Table 3 presents the measured rheological properties of CRS-2TR, CRS-2, CRS-2P, and AC20-TR as well as their final $\mathrm{PG}$ grades based on laboratory testing. As shown from these results, the AC20-TR and CRS-2P binder residues had a wider temperature range of performance than the binder residues in CRS-2TR and CRS-2. Although CRS-2 and CRS-2TR had the same PG grade at high temperature, results showed that CRS-2TR was expected to have greater rutting resistance than CRS-2 based on the $G^{*} / \sin (\delta)$ value for the original and RTFO-aged binder residues. In addition, BBR test results showed that CRS-2P had the lowest creep stiffness and the highest m-value when compared to that of the other emulsions. Hence, it is expected that CRS$2 \mathrm{P}$ would exhibit enhanced resistance to thermal cracking compared to the other emulsions. However, the low temperature grade of CRS-2TR $\left(-24^{\circ} \mathrm{C}\right)$ was found similar to that of CRS-2P and AC20-TR. CRS-2 exhibited the lowest $\mathrm{m}$-value amongst all the binders and had a low temperature limit of $-22^{\circ} \mathrm{C}$ as compared to $28^{\circ} \mathrm{C}$ for the other three product types.

\subsection{Fourier transform infrared spectroscopy analysis}

FTIR spectra of all the original binder residues investigated, in wavenumber range of $4000 \mathrm{~cm}^{-1}-400$ $\mathrm{cm}^{-1}$, are shown in Figure 1. As shown in Figure 1, the binder residues had different peaks corresponding to different types of functional groups present in the materials. To identify these groups, respective structural and functional indices were calculated from the band areas measured from valley to valley. As shown in Figure 2, the calculated indices are plotted for original, RTFO and PAV-aged conditions in order to evaluate the effect of aging on the different binder residues. It is observed that the structural groups such as aromatic and aliphatic indices varied with aging conditions. Functional groups such as carbonyl and sulfoxide indices are mostly used to characterize the aging of the binders [10]. As shown in Figure 3, with respect to carbonyl index and sulfoxide index values observed in the PAV- 
aged conditions, all the binders can be ordered as AC20TR $<$ CRS-2TR $<$ CRS-2P $<$ CRS-2. AC20-TR and CRS-2TR had lower carbonyl and sulfoxide indices compared to that of the conventional emulsions indicating that the incorporation of crumb rubber in the binder improved its resistance to aging. Greater carbonyl and sulfoxide index indicate greater oxidation, where oxygen reacts with the perhydroaromatic ring and increases the stiffness of the binders [10].

Table 3. Results of the Superpave PG Testing.

\begin{tabular}{|c|c|c|c|c|c|c|}
\hline Equipment Test \& AASHTO Method & Specification & $\begin{array}{c}\text { Test Temperature } \\
\left({ }^{\circ} \mathrm{C}\right)\end{array}$ & CRS-2 & CRS-2P & AC20-TR & CRS-2TR \\
\hline & \multicolumn{6}{|c|}{ Original Binder Residue } \\
\hline \multirow{4}{*}{$\begin{array}{l}\text { Dynamic Shear, } 10 \mathrm{rad} / \mathrm{s}, \mathrm{G}^{*} / \mathrm{Sin}(\delta), \mathrm{KPa} \\
\text { AASHTO T } 315\end{array}$} & \multirow{3}{*}{$1.00+$} & $58^{\circ} \mathrm{C}$ & 1.48 & - & & \\
\hline & & $64^{\circ} \mathrm{C}$ & 0.991 & 1.38 & 1.56 & 1.09 \\
\hline & & $70^{\circ} \mathrm{C}$ & - & 0.724 & 0.846 & 0.547 \\
\hline & \multicolumn{6}{|c|}{ Tests on RTFO } \\
\hline \multirow{4}{*}{$\begin{array}{l}\text { Dynamic Shear, } 10 \mathrm{rad} / \mathrm{s}, \mathrm{G}^{*} / \mathrm{Sin}(\delta), \mathrm{KPa} \\
\text { AASHTO T } 315\end{array}$} & \multirow{3}{*}{$2.20+$} & $58^{\circ} \mathrm{C}$ & 3.25 & - & & 4.26 \\
\hline & & $64^{\circ} \mathrm{C}$ & 1.43 & 2.57 & 3.49 & 2.03 \\
\hline & & $70^{\circ} \mathrm{C}$ & - & 1.36 & 1.85 & \\
\hline & \multicolumn{6}{|c|}{ Tests on (RTFO+PAV) } \\
\hline \multirow{4}{*}{$\begin{array}{l}\text { Dynamic Shear, } 10 \mathrm{rad} / \mathrm{s}, \mathrm{G} * \operatorname{Sin}(\delta), \mathrm{KPa} \\
\text { AASHTO T } 315\end{array}$} & \multirow{4}{*}{$5000-$} & $10^{\circ} \mathrm{C}$ & - & 5990 & & \\
\hline & & $13^{\circ} \mathrm{C}$ & 6080 & 4220 & 6930 & \\
\hline & & $16^{\circ} \mathrm{C}$ & 4540 & - & 4810 & 5695 \\
\hline & & $19^{\circ} \mathrm{C}$ & & & & 3955 \\
\hline \multirow{3}{*}{$\begin{array}{l}\text { Bending Beam Creep Stiffness, S, (MPa) } \\
\text { 60s } \\
\text { AASHTO T } 313\end{array}$} & \multirow{3}{*}{$300-$} & $-12^{\circ} \mathrm{C}$ & 77 & 58.5 & & \\
\hline & & $-18^{\circ} \mathrm{C}$ & 196 & 148 & 199 & 207 \\
\hline & & $-24^{\circ} \mathrm{C}$ & - & 278 & 359 & 396 \\
\hline \multirow{3}{*}{$\begin{array}{l}\text { Bending Beam Creep Stiffness, m-value, } \\
\text { 60s } \\
\text { AASHTO T } 313\end{array}$} & \multirow{3}{*}{$0.300+$} & $-12^{\circ} \mathrm{C}$ & 0.320 & 0.372 & & \\
\hline & & $-18^{\circ} \mathrm{C}$ & 0.290 & 0.324 & 0.316 & 0.310 \\
\hline & & $-24^{\circ} \mathrm{C}$ & - & 0.287 & 0.280 & 0.266 \\
\hline \multicolumn{3}{|c|}{ PG Grading } & PG 58-22 & PG 64-28 & PG 64-28 & PG 58-28 \\
\hline
\end{tabular}

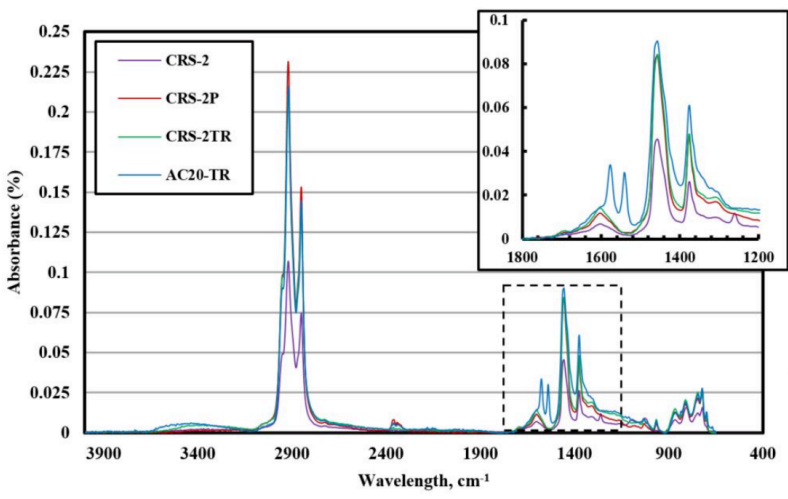

Fig. 1. FTIR spectra of unaged binders.

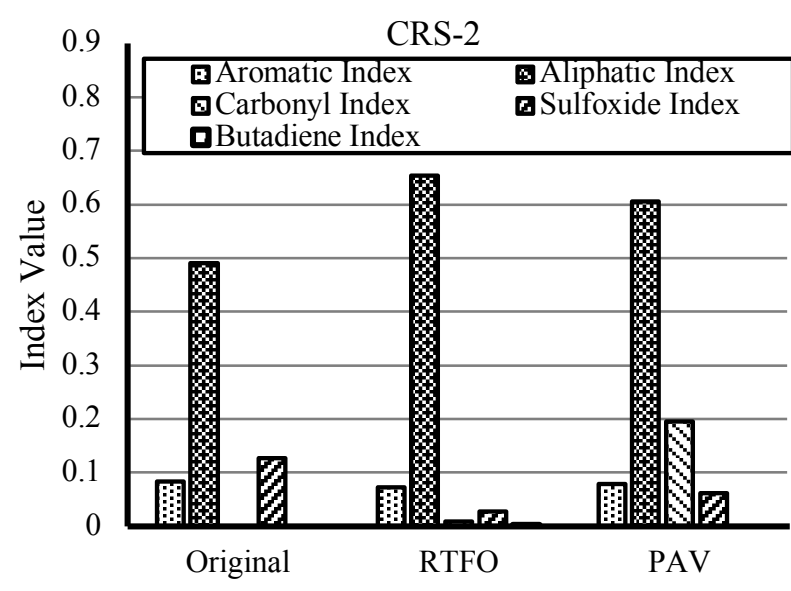

(a)

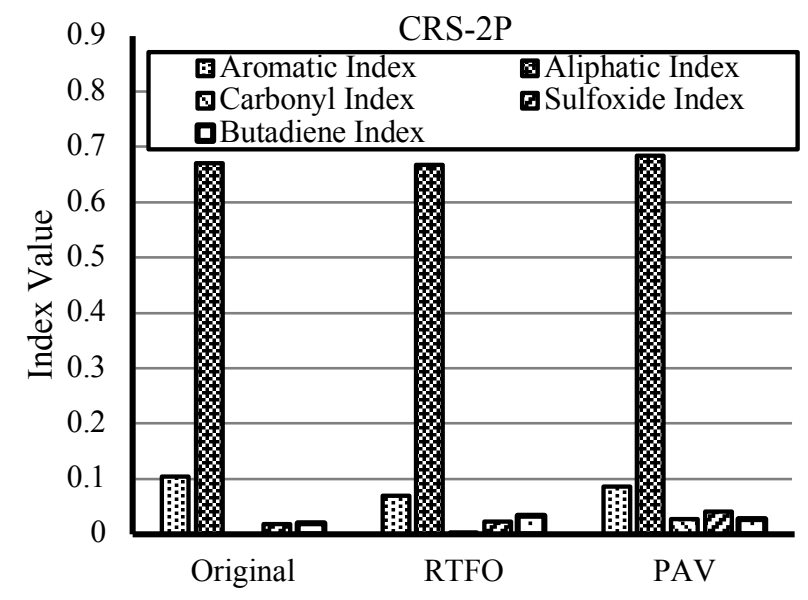

(b)

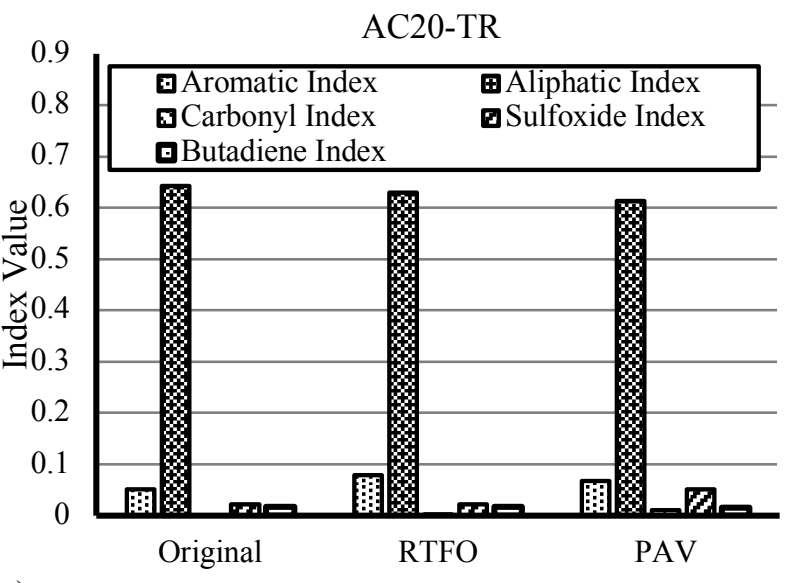




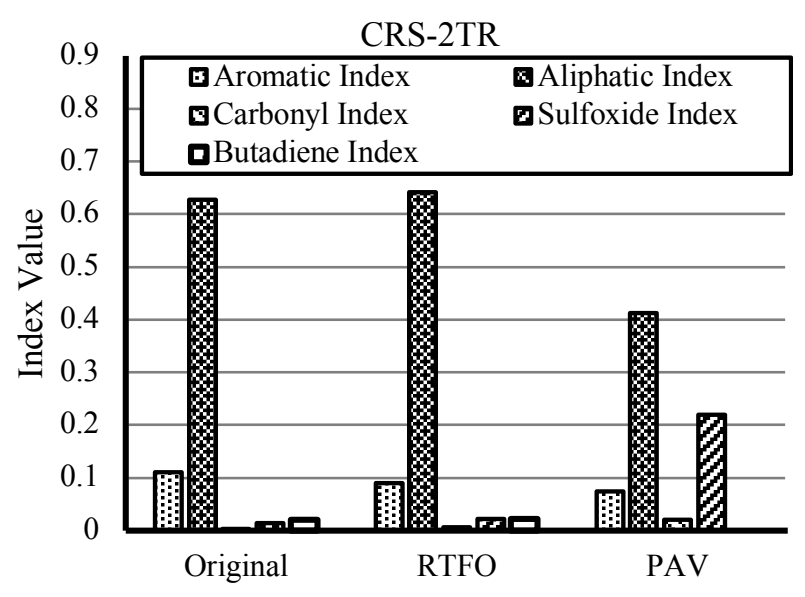

(d)

Fig. 2. Variation of functional indices for different types binder.
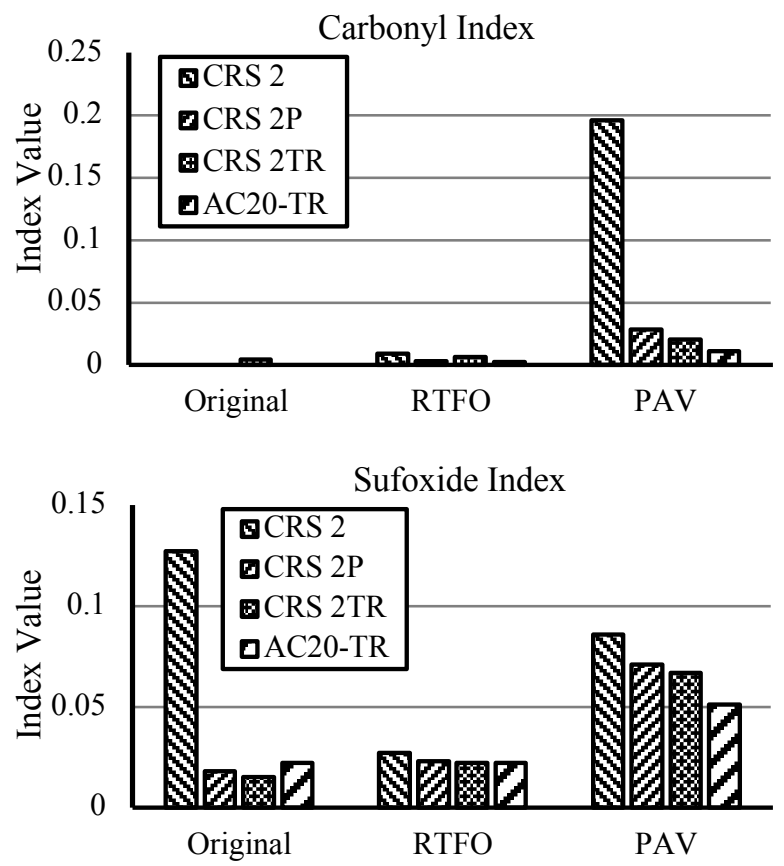

Fig. 3. Variation of carbonyl and sulfoxide index for different types binder.

\subsection{High-pressure gel permeation chromatography analysis}

Figure 4 shows the molecular size distribution for the original, RTFO, and PAV-aged binders obtained from the HP-GPC test results. Fractional distribution of the binders was characterized in two groups: (1) high molecular weight (HMW), which is defined by the molecular fraction with a molecular weight of 3,000 Daltons or more and (2) low molecular weight, which is defined by the molecular fraction with a molecular weight of 3,000 Daltons or less. It had been reported that these groups have significant influence on pavement performance as increased HMW content results in increased brittleness of the binder with aging [11]. It can be observed from the figure that with different aging conditions such as RTFO and PAV, the LMW content in the binder residues decreased and the HMW content increased. Therefore, it is concluded that the oxidation of the binder residues resulted in a loss of LMW. It can be also observed from the figure that CRS-2TR and AC20TR exhibited higher HMW content than conventional emulsions possibly due to the presence of crumb rubber in the binder; the molecular weight of rubber typically ranges from 100,000 to $1,000,000$ Daltons. The HMW content increased significantly with aging for all binder residues. Past research studies conducted by the authors concluded that with the increase in the content of LMW, the elongation properties of the binder also increased at intermediate and low temperatures [12].


Fig. 4. Molecular fractional distribution for different types of binders (upper left - original, upper right - RTFO-aged, and bottom - PAV-aged).

\section{Conclusions}


Based on the results of the experimental investigation, the following conclusions are drawn:

- Superpave testing showed that AC20-TR and CRS$2 \mathrm{P}$ binders had a wider range of performance than the base binders in CRS-2TR and CRS-2. However, the low temperature grade of CRS-2TR $\left(-24^{\circ} \mathrm{C}\right)$ was found similar to that of CRS-2P and AC20-TR.

- The aging of the binders was characterized in terms of the carbonyl and sulfoxide indices where the binders can be ordered as AC20-TR $<$ CRS-2TR $<$ CRS-2P $<$ CRS-2. This indicates that the addition of crumb rubber improved the emulsion's resistance to aging.

- Rubberized emulsion and binder exhibited higher HMW content than conventional emulsions possibly due to the presence of crumb rubber in the binder. Furthermore, the HMW content increased noticeably with aging for all binder residues.

\section{References}

1. W. Temple, et al., (2002). Performance of Louisiana's Chip Seal and Microsurfacing Program. Transportation Research Record: Journal of the Transportation Research Board, 1795(02), 3-16.

2. J. Kiefer, T. Collling, and S. Farrey. (2017). Effective Modelling of Extended Service Life for Pavement Treatments. Transportation Research Record: Journal of the Transportation Research Board, (17), 1-15.

3. D.D. Gransberg. (2005). Chip Seal Program Excellence in the United States. Transportation Research Record: Journal of the Transportation Research Board, 1933, 72-82.

4. A. Rajagopal. (2010). Effectiveness of Chip Sealing and Micro Surfacing on Pavement Serviceablity and Life,

5. R. G. Hicks, et al., (1995). Crumb rubber modifier (CRM) in asphalt pavement: Summary of practices in Arizona, California, and Florida,

6. B. Choubane, et al., (1999). Ten-Year Performance Evaluation of Asphalt-Rubber Surface Mixes. Transportation Research Record: Journal of the Transportation Research Board, 168(1), 10-18.

7. H. Wang, et al., (2012). Laboratory evaluation on high temperature viscosity and low temperature stiffness of asphalt binder with high percent scrap tire rubber. Construction and Building Materials, 1, $583-590$.

8. H.U. Bahia, and R. Davies. (1994). Effect of crumb rubber modifiers (CRM) on performance-related properties of asphalt binders. AAPT, 63, 414-438.

9. J. Lamontagne, et al., (2001). Comparison by Fourier transform infrared (FTIR) spectroscopy of different ageing techniques: application to road bitumens. Fuel, 80(4), 483-488.
10. J.C. Petersen, (2009). A Review of the Fundamentals of Asphalt Oxidation: Chemical, Physicochemical, Physical Property, and Durability Relationships, Washington DC.

11. M. Hassan, et al., (2014). Variability and characteristics of recycled asphalt shingles sampled from different sources. Journal of Materials in Civil Engineering, 26(4), 748-754.

12. M.A. Elseifi, et al., (2010). Relationship between Molecular Compositions and Rheological Properties of Neat Asphalt Binder at Low and Intermediate Temperatures. Journal of Materials in Civil Engineering, 22(12), 1288-1294. 